\title{
E-learning rhetoric, creativity and innovation
}

In this issue of $A L T-\mathcal{F}$ we have five papers that cover a range of policy, evaluation and development issues. The first paper, by Smith, sets the scene for the remaining papers with its focus on policy and how this may be influenced by rhetoric, and in turn may influence creativity and innovation. In 'From flowers to palms: 40 years of policy for online learning', Smith presents a review of learning technology-related policy over the past 40 years. The purpose of the review is to make sense of the current position in which the field finds itself, and to highlight lessons that can be learned from the implementation of previous policies. Smith concludes:

\footnotetext{
The creativity of the early adopters, who matched tools and resources closely to student learning need ... has been overlooked in more recent strategically intentioned developments, but current funding may be beginning to redress this balance. Lessons learned from the demise of the UkeU may signal the end of 'big systems' and a return to innovation, rather than further sustaining Blunkett's ... rhetoric of e-learning as economic necessity ...
}

The remaining papers in this issue certainly present e-learning as a pedagogic rather than an economic necessity. For example, Creanor and Walker examine the pedagogy of transnational online learning from the perspective of communities of practice and learning architectures, while Wheeler, Kelly and Gale explore how a Managed Learning Environment can be designed to promote problem-based learning and situated cognition. In 'Learning architectures and negotiation of meaning in European trade unions', Creanor and Walker describes a project that evaluates a European project focused on two key activities: developing a networking strand to support cross-border sectoral trade union activities, and developing a computer-mediated distance learning for cross-border trade union education. Out of these developments, new pedagogical architectures and social processes emerged. Creanor and Walker use Wenger's concept of 'communities of practice' (CoPs) as a framework for discussing their evaluation data. They conclude:

Communication technologies are vital to the future development of transnational collaboration but, rather than experimenting with cutting edge tools, we would argue that the focus should be on the nuances of the interaction, the role of the 'broker' and the impact of the design. If the development of online learning and CoPs in the trade union sector is to be encouraged, continuing investigation of the emerging pedagogical and social processes, and the relationships between them, is essential. 
In 'The influence of online problem-based learning on teachers' professional practice and identity', Wheeler et al. describe the design of a managed learning environment called MTutor, which is used to teach an online Masters Module for teachers. In describing the design of MTutor, Wheeler et al. highlight the pedagogic value of problem-based learning (PBL), situated cognition and ill-structured problems:

Teachers tend to become convinced of the efficacy of the higher cognitive level of engagement PBL yields, and often change their style to accommodate it in their own professional practice. Furthermore, mature, full-time professionals prefer the flexibility that online learning affords, often in spite of the many accompanying problems and issues.

The papers in this issue may also challenge us to examine what we understand by creativity and innovation in e-learning. For example, the experiences of Bracher, Collier, Ottewil and Shepherd suggest that if technologies such as video streaming are to be used effectively, traditional roles and structures may need to change, while Lukusiak, Agosthinho, Bennett, Harper, Lockyer and Powley propose a learning design framework, which is underpinned by considerations of how to create effective learning experiences. In 'Accessing and engaging with video streams for educational purposes: experiences, issues and concerns', Bracher et al. present a case study of their experiences of using a video with undergraduate and postgraduate health care students. They reflect on the use of the video before and after it was streamed and highlight key issues of access and engagement.

... using streaming media successfully will also require both lecturers and students to change their traditional roles and expectations ... in some respects students will need to become more 'independent' but teaching staff will need to work less independently as they embrace the practicalities of teamwork.

In 'Learning objects and learning designs: an integrated system for reusable adaptive and shareable learning content', Lukusiak et al. propose a system, the Smart Design Learning Framework, designed to support the development of pedagogically sound learning material within an integrated, platform independent structure. Lukusiak et al. propose their system as an alternative to what they describe as 'pedagogically neutral systems'.

Jane Seale 